\title{
Sibling birth order, use of statutory measures and patterns of placement for children in public care: implications for international child protection systems and research
}

\author{
Gillian Henderson $^{\text {a }}$, Christine Jones ${ }^{\text {b }}$, Ruth Woods ${ }^{\text {c }}$ \\ a Scottish Children's Reporter Administration, Honorary Research Fellow, School of \\ Social Work \& Social Policy, University of Strathclyde, Glasgow, UK \\ ${ }^{\mathrm{b}}$ School of Social Work \& Social Policy, University of Strathclyde, Glasgow, UK \\ ${ }^{c}$ School of Applied Social Studies, Robert Gordon University, Aberdeen, UK
}

\begin{abstract}
Public care of abused and neglected children is one important element of statutory intervention which aims to address the major global challenge of protecting children from abuse and neglect. Where a child is part of a sibling group, this introduces particular challenges with regard to meeting the needs of all those affected. This paper presents findings from one of the first studies examining birth order effects on statutory intervention patterns for looked-after siblings. The experiences and outcomes of children were compared depending on maternal birth order at the time of data collection. We found strong evidence that the length of time from first referral of a child deemed at risk to first statutory intervention is greater for first-born than for last-born children and firstborn children are significantly older than last-born children when they are first placed on statutory measures. The study concludes that first-born siblings may be particularly vulnerable to delayed statutory intervention and the cumulative effects of harm and certain routes to permanence may be less available to them. We argue for increased focus within international child welfare policy and practice on timely and intensive assessment of first-born children, where risk of maltreatment is identified, in order to address potential inequalities of access to protection. A focus on risk introduced by systemic factors within legal and welfare systems in addition to risk introduced by perpetrators of abuse is needed. We also argue for greater research attention to, and more precise measurement of, birth order as a variable in studies of the looked-after population.
\end{abstract}




\section{Highlights}

- First-born children are significantly older than last-born children when they are first placed on statutory measures.

- The length of time from first referral to first statutory intervention is greater for first-born than for last-born children.

- First-born children are significantly older than last-born children when they are first accommodated and significantly more last-born than first-born children are adopted.

- We conclude that first-born children may be particularly vulnerable to the cumulative effects of harm and subject to delayed statutory intervention.

\section{Keywords}

Siblings; birth order; adoption; permanence; Children's Hearings System; looked-after children 


\section{Introduction}

Protection of children from abuse and neglect is recognised as a major global public health and social welfare challenge (Butchart, Harvey, Mian, and Furniss, 2006). While prevalence rates of child maltreatment vary internationally by type of abuse and cultural context and are influenced by methodological differences between studies, the overall picture is concerning. Meta-analyses of studies have estimated world-wide prevalence rates within general populations at around $18 \%$ in the case of physical abuse (Stoltenborgh, van IJzendoorn, Euser and Bakermans-Kranenburg, 2011), 12\% in the case of sexual abuse (Stoltenborgh, Bakermans-Kranenburg, van IJzendoorn and Alink, 2013 ) and $18 \%$ in the case of neglect (Stoltenborgh, Bakermans-Kranenburg, and van IJzendoorn, 2013).

There is a well developed body of evidence showing that exposure to abuse and neglect is likely to have long-term adverse consequences across children's physical, cognitive, social, emotional and behavioural development (Gilbert et al, 2009; Felitti et al, 1998). While maltreatment in the early years has been highlighted as a particular concern because of the impact it may have on a child's neurobiological development and the attachment process, the negative impact of abuse and neglect has also been shown to continue throughout childhood and adolescence, and into adulthood (Norman, Byambaa, De, Butchart, Scott and Vos, 2012; Ward, Brown and Westlake, 2012).

Public care of abused and neglected children is one important element of statutory intervention to protect the safety of children and aid recovery. The importance of securing a safe and stable care environment in a timely fashion is recognised as especially important (The Care Inquiry, 2013). Within the UK, this must be achieved within the context of policy that places on public bodies responsible for looked-after children a duty to 'promote the upbringing of children by their families wherever consistent with their welfare' (Children Act 1989; Children (Scotland) Act 1995). Where a child is part of a sibling group, this introduces particular challenges with regard to equitably meeting the needs of all those affected (Scottish Government, 2011; Department for Education, 2015).

Considerably more attention has been paid in international studies of the care system to the needs, experiences and outcomes of individual children than sibling groups. One 
factor that has been consistently associated with decision-making and outcomes at various points in a child's journey through care and into permanence is the age of the child. In general, younger age at entry to care has been associated with less adversity (McSherry, Fargas Malet and Weatherall, 2010) and younger age at joining a permanent placement has been found to have the greatest impact on long-term placement stability (Boddy, 2013; Biehal, Ellison, Baker and Sinclair, 2009). It has also been shown that a child's chance of adoption reduces by almost $20 \%$ for each year of delayed intervention (Selwyn, Sturgess, Quinton and Baxter, 2006). As a result, considerable emphasis has been placed within policy on the need to avoid delays (Department for Education 2012).

As research on siblings in public care has grown, age effects have continued to be studied, including attention to the impact on care experiences of age differences between siblings (Shlonsky, Webster, and Needell, 2003; Wulczyn and Zimmerman 2005). This paper focuses on a concept related to, but distinct from, age and age differences, that is, sibling birth order. Birth order research is prolific in psychological research but is a relatively under-researched area within the literature on public care of abused and neglected children. Where it has been studied most attention has been directed towards understanding the relationship between birth order and risk of maltreatment (Isumi and Fujiwara, 2016; Putnam- Hornstein, Webster, Needell and Magruder, 2011; Shen et al, 2016). Our study offers two key contributions to knowledge. First, it demonstrates the methodological importance of differentiating age and birth order effects in order to understand experiences and outcomes of public care. Second, it shifts the emphasis of research on birth order and child protection from risk introduced by perpetrators of abuse towards potential risk introduced by systemic factors, particularly, delays in protection and recovery.

\section{Current knowledge regarding the public care of abused and neglected siblings and birth order effects}

Evidence relating to public care of abused and neglected siblings has been building over the last two decades. To date, this has mainly focused on the imperative to place lookedafter siblings together, where in a child's best interests, and on child outcomes where this is fully, partially or not achieved (see recent reviews by Jones, 2016; McCormick, 2010; and Meakings, Sebba and Luke, 2017). The challenges associated with achieving co- 
residence of looked-after siblings have also been studied and have been found to include children coming into care at different times, experiencing multiple moves, being part of large sibling groups and age and gender differences (Shlonksy, Webster and Needell, 2003). A much smaller number of sibling studies have examined birth order effects on experiences of child maltreatment and child protection. This research has suggested a lack of association between birth order and rates of maltreatment. (Isumi and Fujiwara, 2016; Putnam- Hornstein et al, 2011; Shen et al, 2016) and between birth order and child deaths (Putnam-Hornstein, Cleves, Licht and Needell, 2013; Vincent and Petch, 2012). However, there is some indication of a potential effect of birth order on statutory interventions and decision-making (Shlonsky et al, 2003; Tarren-Sweeney and Hazell, 2005). This study intends to build further on this latter body of work which we describe next.

Two previous studies explicitly report birth order effects on statutory intervention in the lives of maltreated children. Tarren-Sweeney and Hazell (2005) examined the influence of multiple factors on the mental health and socialisation of children in foster placements and kinship care in Australia including the effect of birth order and sibling placement type. The sample included children aged between four and 11 years old. A paired comparison was conducted of 52 dyads of co-resident siblings. They report that "older" (that is, earlier-born) siblings, on average, entered care at an older age than "younger" (that is, later-born) siblings (mean of 4.7 years compared to 2.9 years). Given that most sibling pairs in their analysis entered care at a similar time or within one month of each other this is unsurprising. However, they also reported that older siblings had been exposed to maltreatment for longer, with twice the number of confirmed maltreatment notifications compared to younger siblings (a mean of 4 and 2 respectively) and a greater number of years between first maltreatment notification and entry into care when compared to their younger siblings (a mean of 2.3 and 1.3 respectively). Shlonsky et al (2003) also distinguished oldest, middle and youngest siblings within a sibling cluster in their study of children in foster care in the United States. From an analysis of birth order effects, they reported that the very youngest in a sibling group were more likely to be placed separately from other siblings than middle or older siblings when a decision was made to split the siblings. 
These studies report important findings about the impact of decision-making on children's experiences but also begin to reveal the complexity of undertaking research relating to birth order with this population of children. Tarren-Sweeney and Hazell (2005) report data relating to 'older' and 'younger' sibling pairs. However, these categories are ascribed to children who were placed together, entered care at a similar time and are likely to have other shared characteristics. It is possible that different results would emerge if data were available on all siblings within a family constellation or if different pairs were compared. This may lead to non-significant findings relating to decision making and outcomes becoming significant or vice versa. The study reported here aimed to build on previous findings relating to referral and decision-making practices for siblings by increasing the diversity within the sample and differentiating in the analysis sibling pairs who underwent an intervention (such as becoming accommodated) concurrently and at different times. We developed the following five hypotheses related to key stages of the care journey:

1. First-born children will be significantly older than last-born children at first referral.

2. The length of time from first referral to first compulsory statutory measure will be greater for first-born than for last-born children.

3. First-born children will be significantly older than last-born children when they are first placed on compulsory statutory measures.

4. First-born children will be significantly older than last-born children when they are first accommodated.

5. Building on the preceding hypotheses, we predicted that, as a result of delayed intervention, of those children who are placed permanently away from home with strangers, significantly more last-born than first-born children will be adopted.

\section{Methods}

\subsection{Selection of sample}

The research reported here was undertaken in Scotland where statutory intervention to protect children at risk is organised through the Children's Hearings System. Operating since 1971, the introduction of the Hearings System shifted responsibility for decisionmaking in cases where children's welfare, safety or behaviour were a concern from a formal court-setting to the more informal setting of a Children's Hearing in which lay 
Children's Panel Members are the key decision-makers. They have the power to make Compulsory Supervision Orders (CSOs). These orders may specify that a child be lookedafter at home or placed away from the family home depending on what the Hearing deem to be in the child's best interests (Scottish Children's Reporter Administration, 2013). The Scottish Children's Reporter Administration (SCRA) is the national body responsible for employing Children's Reporters, who decide if a child should be referred to a Children's Hearing, and for the administration of Hearings.

Referral to the Children's Reporter is the most common entry point to the Hearings System. A child is referred when it is considered that they are in need of protection, guidance, treatment or control and that it might be necessary for a CSO to be made. Multiple referrals are made where a sibling group is the focus of concern. In 2015-16, there were 15,329 children referred to the Reporter and 10,379 children and young people who had CSOs. Of these, 5,844 (56\%) were looked after and accommodated and 4,522 (44\%) were looked-after at home (Scottish Children's Reporter Administration, 2016).

The second most common entry to the Hearings System follows a Child Protection Order (CPO) being made by a Court (section 39(1) of the 2011 Act). A CPO is the main measure used to protect a child in an emergency situation, and requires that the child be removed immediately from, usually, their parent(s). In 2015-16, CPOs were granted for 595 children (Scottish Children's Reporter Administration, 2016).

The sample was selected from a previously identified group of children who were the subject of an earlier study of permanence planning and decision-making for looked-after children in Scotland (Henderson, Hanson, Kurlus, Hunt and Laing, 2015). The larger group consisted of a random sample of 293 children who had been subject to CSOs and had Permanence or Adoption Orders made by Sheriff Courts between $1^{\text {st }}$ April 2013 and $31^{\text {st }}$ March 2014. From this sample, 50 unrelated children ('index children'), all of whom had at least one biological sibling, were selected for the study reported here.

The 50 'index' children were selected from seven local authority areas (two city councils, two rural and three mixed urban and rural areas) to ensure a range of contexts was captured. These files and the SCRA Case Management System (CMS) were then used to 
identify the siblings of the 50 'index' children. The task of defining and identifying a sibling relationship in the case of looked-after children can be complex (Jones, 2016; Lery, Shaw and Magruder, 2005). For the purposes of this study the definition was restricted to full and half biological siblings documented in children's records. Using this procedure, a total of 154 biological siblings were identified (52 full siblings, 81 maternal half siblings and 21 paternal half siblings). This allowed us to code maternal birth order of the 50 index children and their full and maternal half siblings. Data regarding statutory intervention were available for 112 children and these are included in the analysis reported here.

\subsection{Characteristics of the sample}

Of the 112 children in the sample, 30 were the first-born in their sibling group; 42 were middle siblings; and 40 were the last-born sibling. Fifty three of the children were male (47\%) and 59 were female (53\%). The majority (106, 95\%) were 'white: English/Welsh/Scottish/Northern Irish/British'. The sample mainly included children who were subject to statutory measures but often at different points in time. All of the index children and approximately $90 \%$ of their siblings aged under 18 were ultimately placed permanently away from their birth parents.

\subsection{Data extraction}

Data collection took place between September and December 2015. Information on the 'index' children and their siblings was obtained from SCRA's CMS and extracted manually from case files held in SCRA's offices. SCRA's case files hold reports from agencies including social work, police, education and health, and statutory documentation and Orders made by Hearings and Courts. Once a sibling had been identified from the 'index' child's case file, CMS was searched to find out if the sibling was ever involved in the Hearings System and, where relevant, to source the location of their case file. Where SCRA did not hold a case file on a sibling, information about them was often available from case file reports on one of more of the siblings.

Data were extracted for checking, cleaning and initial analysis by SCRA personnel. Individual cases were linked by the children's SCRA CMS IDs; no names or other identifiers were recorded. Selected data were transferred securely to university co- 
researchers and imported into SPSS for further analysis. The data were held on encrypted systems to which only the researchers had access.

\subsection{Data analysis}

We begin with initial descriptive analyses incorporating all the children for whom data were available. We then proceed to inferential statistical analyses of sibling pairs. A series of outcomes were compared for first and last-born siblings using paired sample $t$ tests and McNemar's tests.

\subsection{Ethical approval}

Ethical approval to undertake the case file analysis was provided by the $\mathrm{xxx}$ Ethics Committee at the University of xxx (the previous employer of the Principle Investigator xxx). A General Data Sharing Protocol Agreement was put in place between the institutions involved in this study for the purposes of this research. The members of the research team who had access to SCRA's CMS and case files are members of the Protection of Vulnerable Groups Scheme for regulated work with children, and have undergone training on the UK Data Protection Act 1998.

\section{Findings}

\subsection{Description of the use of compulsory measures for the entire sample}

A total of 111 of the 112 children (aged under 18 years) had been referred to the Children's Hearings System. The grounds for first referral for 92 of the 111 children (83\%) were that: 'the child is likely to suffer unnecessarily, or the health or development of the child is likely to be seriously impaired, due to a lack of parental care'. The second most common ground for first referral was due to an offence against children including violent offences, sexual offences, neglect and abandonment - this was relevant to 18 of the 111 children $(16 \%)$.

Information on decision at first referral, including use of compulsory measures, or if the Court had made a protection order were available for 111 children (Table 1). For 71 children (64\%) compulsory measures were imposed following their first referral. It is noteworthy that many of the children who did not have compulsory measures imposed at first referral went on to have compulsory measures following subsequent referrals. 


\section{INSERT TABLE 1}

\subsection{Approach to hypotheses testing}

The statistical analyses to test our hypotheses were conducted using sibling pairs drawn from the 50 index children's families (though did not necessarily include the index child as some were middle siblings). The pairs were made up of the first-born maternal sibling in the family and the last-born maternal siblings for whom data were available. Pairing first-born with last-born (or, in two cases, penultimate) siblings allowed us to maximise the number of sibling pairs in the analysis who underwent each intervention of interest at different times (e.g. first use of compulsory measures or becoming accommodated). This was important because it avoided one of the limitations within Tarren-Sweeney and Hazell's (2005) analysis which included pairs of siblings who predominantly entered care at around the same time.

The inclusion of penultimate siblings is justified for two reasons. Firstly, it keeps the sample size, and thus the power of the statistical analyses, as high as possible. Secondly, it does not diminish the contrast in terms of birth order. In fact, considering all sibling pairs with complete referral data, the mean birth order position of the penultimate siblings is 3.5, which is slightly higher than the mean birth order position of the last-born siblings (3.0). It should also be recognised that birth order can change over time and it is conceivable that some mothers of children in our sample will have gone on to have additional children, thus eventually rendering last-born siblings captured in a crosssectional analysis penultimate siblings.

No data were available for 16 first-born siblings and five last-born siblings, and for some of the remaining children in the dataset the data were incomplete either because recording within files was inadequate or because children were never referred, subject to compulsory measures, or accommodated. Therefore the number of children entered into analyses varied.

INSERT TABLE 2 
Paired sample $t$ tests were used to test hypotheses 1 to 4 , which all concerned age at intervention or duration from one event to another. In some cases, noted below, the data were not normally distributed (as assessed by a Shapiro-Wilks test and inspection of histograms). In these cases, the paired samples $t$ test was accompanied by a nonparametric Wilcoxon test (which does not make assumptions about normality). In all cases, findings of the two tests with respect to significance at the 0.05 level were the same. Where outliers (cases more than 1.5 times the interquartile range) were detected, pairedsample t tests were run with and without the outliers. In all cases, exclusion of outliers did not have a substantive effect on the results, therefore we report analyses including outliers. Statistical tests results, means and standard deviations for hypotheses 1 to 4 are reported in Table 3. A McNemar's test was used for hypothesis 5, which involved paired nominal data (type of permanent placement).

In some pairs, both children underwent the intervention of interest (e.g. first referral or first use of compulsory measures) at the same time. This was the case for two of 23 pairs (9\%) for first referral, nine of 24 pairs (38\%) for first compulsory measures, and 11 of 23 pairs $(48 \%)$ for first accommodation. In these cases, first-born children were inevitably older than their youngest-born siblings. For hypotheses 1, 3 and 4, we analysed the data both with and without these 'joint' pairs and both analyses are reported for each hypothesis in Table 3.

Hypothesis testing was complicated by the fact that over the years represented in the dataset, there was a trend in Scotland towards earlier first referrals and compulsory measures, evidenced in SCRA's national data. The mean age at first referral, for those children who went on to be placed on CSOs, was 6.622 years $(n=1,813)$ in 2003-04 (the first year this information is available), falling to 4.363 years $(n=1,264)$ in 2012-13 (the last year in which a child in our sample was first referred). Similarly, the mean age at first CSO was 9.177 years $(n=3,602)$ in 2003-04, and 7.302 years $(n=3,044)$ in 2012-13. National data on mean age at first accommodation were not available, but it is plausible that this has also decreased over the relevant time period.

Since interventions usually occurred at an earlier point in time for first-born siblings than interventions for their last-born siblings, there was a danger that any significant 
differences found between the age at intervention of first and last-born siblings result from this national trend, rather than from anything to do with birth order.

For hypotheses 1 to 3, we took national trends into account by subtracting national mean age at intervention for the year in which the intervention took place, from the age of the children in the sample. For instance, for a first-born child whose first referral was in early 2005, we subtracted the national mean age at first referral (for those children who went on to be placed on compulsory measures) in 2004-05 from the first-born child's age at first referral. (SCRA annual means cover the period between year midpoints; e.g. 200405 covers the period from mid-2004 to mid-2005). We report statistical results using these adjusted ages along with the findings for unadjusted ages below. The sample size for these analyses is smaller because national means were only available from 2003-04 on, therefore pairs with an earlier first intervention could not be included.

Means and standard deviations for the paired siblings included in the hypothesis testing are provided in Table 3. Note that adjusted mean ages are negative, because the sample's mean age at intervention was lower than the national mean age at intervention. This is probably because all children in the sample were from families from which at least one child was accommodated. Accommodation away from home is more common for younger than older children (Henderson, Black and Lamb, 2014). It should be noted that the national data is on all children who went onto be placed on compulsory measures of supervision, and that those in our sample represent the minority who go onto to have Adoption or Permanence Orders.

\subsection{Effects of birth order on timing of state interventions}

The findings relating to hypotheses 1 to 3 which deal with the effects of birth order on timing of first referrals and first use of compulsory measures will now be presented. For each hypothesis, the key finding will be presented. Full details of the statistical analyses, along with means, standard deviations, and confidence intervals for the population, can be found in Table 3.

HYPOTHESIS 1. First-born children will be significantly older than their last-born siblings at first referral / CPO. 
Key finding: Using ages adjusted for national trends, the age difference between first and last-borns at first referral / CPO only approached significance. Thus we cannot confidently assert that this hypothesis was supported.

HYPOTHESIS 2. The length of time from first referral / CPO to first compulsory measures will be greater for first-born children than for their last-born siblings.

Key finding: This hypothesis was supported. The mean duration from first referral / CPO to first compulsory measures was 30.4 months greater for the first- compared to last-born siblings in our sample (using ages adjusted for national trends). There is a $95 \%$ chance that amongst all children in Scotland taken into care, the duration from first referral to statutory measures is at least 4.2 months longer for first than last-born siblings, and may be considerably longer.

HYPOTHESIS 3. First-born children will be significantly older than their last-born siblings when they are first placed on compulsory measures

Key finding: Although no significant difference was found between the age of first-born and last-born siblings at first referral / CPO (see Hypothesis 1), first-born children were significantly older than their last-born siblings when they were first placed on compulsory measures - this held even when excluding those sibling pairs who were placed on compulsory measures at the same time as each other. The mean difference in age in the sample (based on ages adjusted for national trends) was 36.3 months; for the Scottish population of children taken into care, we can be $95 \%$ confident that first-born siblings experience a delay of at least 18 months relative to their youngest siblings. This reduces to a still substantial minimum of 6.9 months if we exclude siblings who are placed on compulsory measures at the same time.

\subsection{Associations between birth order and placement decisions}

HYPOTHESIS 4. First-born children will be significantly older than their last-born siblings when they are first accommodated. 
Key finding: The hypothesis was supported. First-borns were a mean of 46.3 months older than last-born siblings at first accommodation, and even excluding those accommodated on the same day, there is a $95 \%$ chance that first-borns in the Scottish care population experience a delay of over 18 months relative to their youngest siblings, before being accommodated. However, we are unable to discount the possibility that this difference may be partially or wholly the result of changing national trends in addition to, or instead of, a consequence of birth order because there were no national data available on trends over the period concerned.

\section{INSERT TABLE 3}

HYPOTHESIS 5. Of those children who are placed permanently away from home with strangers, significantly more last-born than first-born children will be adopted

Key finding: This hypothesis was supported. While placement type was identical for 11 sibling pairs in the sample, only the youngest sibling was adopted in all of the remaining 5 pairs.

An exact McNemar's test found that the difference between first and last-born siblings was significant, $N=16,1$-tailed $p=.032$. Eleven sibling pairs had the same placement type (adoption for seven pairs, Permanence Orders and long term foster or residential for four). For all five remaining pairs, the first-born child was placed in long-term foster or residential care, and the last-born sibling was adopted. In other words, seven of 16 firstborn children were adopted (44\%) compared with 12 of 16 last-borns (75\%).

Adoption rates have increased slightly over the last 15 years in Scotland, offering an alternative explanation for the difference between first and last-born siblings. Unfortunately, we did not record dates for anticipated permanent placements. Instead we calculated median dates of first accommodation for first and last-born siblings. This was 2009 for first-borns and 2010 for last-borns; i.e. a gap of only one year. The largest oneyear difference in number of children adopted from 2009 onwards was between 2014 (455) and 2015 (504), representing an increase of 11\% (National Records of Scotland, 
2016). Differences between other years in this period were much smaller, and some were negative (e.g. rates fell from 2013 to 2014 by 7\%). The modest and inconsistent trend in national adoption rates do not therefore provide a compelling alternative explanation for the finding that last-born siblings in our sample were adopted significantly more often than those first-born.

\section{Discussion}

\subsection{Implications of the study for policy and practice}

The first important finding of the study was that while there was no convincing evidence that first-born children were significantly older than last-born children at first referral, we found strong evidence that the time from first referral to first compulsory measure was longer for first-born than for last-born children and first-born children were significantly older than last-born children when they are first placed on compulsory measures. This latter finding remained significant whether children were placed on compulsory measures at the same time or at different times. This adds weight to the findings of Tarren-Sweeney and Hazell (2005) regarding differences between earlier and later-born siblings' history of intervention and suggests, despite different populations and jurisdictions, that these issues endure across diverse policy and practice contexts. Taken together these findings are supportive of our argument to focus on both age and birth order effects in studies of experiences and outcomes of looked after children and more specifically to pay attention to the vulnerabilities of first-born children.

There is a heavy emphasis within child welfare policy on avoiding unnecessary delays in child protection yet no attention has thus far been directed towards causes of delay for first-born children. Our data are not able to provide an explanation for the delay and further investigation is needed to understand this and the consequences for a child's wellbeing. It may be that some delays may result from the complex balancing of welfare needs of children, for example, early removal may lead to sibling estrangement when subsequent children are born. It may also be that delay is caused by systemic weaknesses. Two key aspects of delay experienced by children are explored in existing literature, delay within social work processes and delay within legal processes. Previous research has suggested that services tend to overestimate the capacity of families to improve and set high thresholds for intervention which can expose children to cumulative harm and 
compromise their development (Farmer and Lutman, 2010; Ward et al, 2012). Ward and colleagues (2012) also highlight that courts have been characterised as over-optimistic and too willing to give families another chance to change. These potential delays are likely to have a disproportionate effect on older, that is, first-born children who may become the test-cases for optimistic decisions made by social workers, courts or Children's Hearings. There is much variation internationally regarding the use of voluntary and statutory measures to protect children (Burns, Pösö, and Skivenes, 2016). The differential use of these measures with first and subsequent-born children and the causes and consequences of delay is, therefore, an important topic for future research.

Another under-researched area of practice that our findings throw into focus is the assessment of risk and its relationship to family development. The body of literature concerned with assessment of risk factors for child maltreatment consistently identifies previous involvement of a family with child protection services as an indicator of risk of further abuse of a child or a sibling (Dakil, Sakai, Lin and Flores, 2011; Eastman, Mitchell and Putnam-Hornstein, 2016). Eastman et al (2016) found that an initial allegation of neglect and family history of Child Protection Service involvement were strong predictors of infant referral to these services. Research in Scotland has shown that it is the history of care of older children that often results in decisions being made to remove younger and older children from their parent(s) (Henderson et al, 2015), and research in England has found that actions are taken earlier in the lives of infants born to mothers who have a history of children being removed (Broadhurst et al, 2015). This raises a question about whether this evidence of history of maltreatment is relied upon too heavily in decisionmaking with less attention to broader risk indicators. This again is likely to disadvantage first-born siblings. While there may be limited information available when new parents first come to the attention of services, the onus must be on professionals to look at a child's wider circumstances and get to know them rather than focusing on a single episode (Scottish Government, 2010). More specific statutory guidance in such circumstances is likely to be welcomed by practitioners.

The findings of this study also indicate a subsequent delay in compulsory measures as children's care journey unfolds. Our analysis found evidence that first-born children are significantly older than last-born children when they are first accommodated. Whilst we 
cannot rule out national trends as an alternative explanation for the birth order difference in age at first accommodation, it seems highly likely that the delay eldest children experience with respect to compulsory measures would result in a delay in a child first being accommodated away from home. This builds on Tarren-Sweeney and Hazell's (2005) study which found the same pattern but was restricted to data on children who predominantly entered care at or around the same time.

Finally, we found evidence that significantly more last-born than first-born children were adopted suggesting that certain routes to permanence become unavailable to first-born children as a result of delay. Given that the majority of first-born children were ultimately placed permanently away from home it is likely that they were exposed to harm over longer periods than subsequently born siblings and are, therefore, particularly vulnerable to the long-term cumulative effects of maltreatment. We would not wish to suggest a hierarchy of permanence that favours adoption over other types of permanent placement such as kinship care (The Care Inquiry 2013) but would stress the importance of stability and quality of care. First-born siblings could be considered to be especially disadvantaged as a result of their cumulative early life experiences and may face reduced likelihood of having a secure and permanent home. Given this, we would suggest that a case can be made for intensive assessment and early intervention when a first child is born and concerns are raised in order to ensure that evidence is gathered in a timely and rigorous manner and to avoid children being unnecessarily exposed to risk or suboptimal care. This may go some way towards mitigating longer-term risk. Early intensive family support and rehabilitation with single-child families could also reduce the high incidence of repeat care proceedings noted by Broadhurst et al. (2015). Our findings also suggest that support should be sustained throughout the first-born child's care journey and is likely to be needed by these children and their carers when in permanent placements.

\subsection{Conceptual issues and implications of the study}

Age has consistently been identified as a key variable in studies of the experiences and outcomes of looked-after children. This study suggests that birth order is also an important variable to include in such research. Within sibling research more generally, there has been a longstanding interest in birth order starting with the work of Adler (1964). While some more deterministic applications of his work have come to be treated 
with some scepticism (Shulman and Mosak, 1977) the research reported here suggests a promising alternative use of birth order data, that is, to identify potential anomalies or inequalities within legal and welfare systems. In order to progress this field of study we suggest that more precise use of terminology is needed in research. It is typical in studies of children in public care to refer to experiences and outcome of 'younger' and 'older' siblings (Tarren-Sweeney and Hazell 2005; Shlonksy,Webster and Needell 2003). In order to distinguish age and birth order effects we suggest that terms such as 'earlier born' or 'later born' are used. In some instances an absolute measure of birth order may be more appropriate than a relative measure of birth order in which case terms such as 'first-born', 'second-born', 'middle-born or 'last-born', for example, may provide a more precise indication of approach to measurement.

The study also suggests that birth order may be a useful variable in studies of child maltreatment more broadly, that is, beyond those that focus on experiences and outcomes of public care. For example, it has been shown that children who are scapegoated in maltreating families are more likely to be older and to be exposed to physical or sexual abuse (Hamilton-Giachritsis and Browne, 2005). While research has not found birth order to affect the likelihood of the child experiencing abuse (Isumi and Fujiwara, 2016; Putnam- Hornstein et al, 2011; Shen et al, 2016), relationships between birth order and types or nature of abuse have not been studied, as far as we are aware, and may offer new insights into child maltreatment and family structure.

\subsection{Limitations of the study}

A large proportion of the children included in this research represent a very particular sub-sample of looked-after children, that is, those placed permanently away from home. The numbers of children who go on to be adopted or are in permanent foster, residential or kinship care in Scotland are less than $10 \%$ of those who are looked-after (Henderson et al, 2015). Given the level of vulnerability of this group, however, they are an important focus of study. Future research should extend the sample of looked after children to include a range of legal and placement outcomes. Because relevant data for first-born and last-born siblings were often incomplete, sample sizes for the inferential statistics were modest. Further research with larger sample sizes would be helpful, in order to narrow confidence intervals, and in particular to assess hypothesis 1, regarding age at first 
referral, more confidently. One further limitation of this and many other sibling outcome studies is the use of retrospective designs making it difficult to establish causation. Prospective and longitudinal designs are necessary.

\subsection{International significance of the study}

While this study was conducted in Scotland and drew on data from a particular statutory system designed to protect children, it raises some universal questions that are of international importance. The lack of research attention to birth order effects on the public care of abused and neglected children is an international phenomenon. This study provides evidence of the value of addressing this issue through further research. It highlights the importance of conceptually distinguishing age, age difference, family structure and birth order and indicates potential fruitful avenues of study such as assessment of risk, referral and decision-making practices and timely intervention. It also highlights a need for qualitative research to explain decision-making regarding first and subsequent-born siblings. The Children's Hearings System in Scotland is characterised by its use of lay decision-making. There are a number of other jurisdictions that have adopted models of lay involvement of various kinds including Finland, Denmark and Norway (Hill, Welch and Gadda, 2017). This study indicates that comparative studies of system responses and outcomes for first and subsequent-born siblings within these different jurisdictions may also shed light on wider macro and micro influences on decision-making.

\section{Conclusions}

This is one of the first studies to examine associations between birth order and referral to statutory services, statutory decision-making and permanence outcomes for children at risk of maltreatment. The analysis found evidence of delays in the use of compulsory measures for first-born children compared to last-born children. It also produced evidence that first-born children are significantly older than last-born children when they are first accommodated and that significantly more last-born than first-born children are adopted.

In the paper we have made a case for greater emphasis within policy and practice on the needs of first-born children in order to protect children from harm and its associated longterm consequences. However, we acknowledge that this raises difficult questions about 
the mitigation of risk in situations involving vulnerable families and children and we do not underestimate the complexity of the challenge faced by both legal and welfare systems which need to balance the right to family life with the right to freedom from harm. We have also provided evidence of the value of placing greater research attention on birth order as a variable in studies of the experiences of, responses to and outcomes of child maltreatment. Progress in these areas requires both political will and inter-disciplinary co-operation to continue to build an evidence-base and apply this across legal and welfare boundaries. 


\section{References}

Adler, A. (1964). Problems of neurosis. New York: Harper \& Row.

Albert, V.N. \& King, W.C. (2008). Survival analyses of the dynamics of sibling experiences in foster care. Families in Society: The Journal of Contemporary Social Services, 89, 533-541.

Allnock, D. \& Miller, P. (2013). No one noticed, no one heard: a study of disclosures of childhood abuse. London: NSPCC.

Barclay, K. (2015). Birth Order and Educational Attainment: evidence from fully adopted sibling groups. Intelligence, 48, 109-122.

Biehal, N., Ellison, S., Baker, C. \& Sinclair, I. (2009). Characteristics, Outcomes and Meanings of Three Types of Permanent Placement - Adoption by Strangers, Adoption by Carers and Long-Term Foster Care. London: Department for Children, Schools and Families.

Boddy, J. (2013). Understanding Permanence for Looked After Children: A review for the Care Inquiry. London: House of Commons.

Broadhurst, K., Alrouh, B., Yeend, E., Harwin, J., Shaw, M.., Pilling, M., ... \& Kershaw, S. (2015). Connecting Events in Time to Identify a Hidden Population: Birth Mothers and Their Children in Recurrent Care Proceedings in England. British Journal of Social Work, 45, 2241-2260.

Burns, K., Pösö, T., \& Skivenes, M. (Eds.). (2016). Child welfare removals by the state: A cross-country analysis of decision-making systems. Oxford University Press.

Butchart A., Harvey A. P., Mian M., \& Furniss T. (2006). Preventing child maltreatment: A guide to taking action and generating evidence. Geneva, Switzerland: World Health Organization and International Society for the Prevention of Child Abuse and Neglect. 
Calder, M., McKinnon, M. \& Sneddon, R. (2012). National Risk Framework to support the Assessment of Children and Young People. Edinburgh: Scottish Government.

Dakil, S. R., Sakai, C., Lin, H., \& Flores, G. (2011). Recidivism in the child protection system: Identifying children at greatest risk of reabuse among those remaining in the home. Archives of pediatrics \& adolescent medicine, 165(11), 1006-1012.

Department for Education (2012). An Action Plan for Adoption: Tackling Delay. London: Department for Education.

Department for Education (2015). The Children Act 1989 Guidance and Regulations. Volume 2: Care Planning, Placement and Case Review. London: Department for Education.

Eastman, A. L., Mitchell, M. N., \& Putnam-Hornstein, E. (2016). Risk of re-report: A latent class analysis of infants reported for maltreatment. Child abuse \& neglect, 55, 22 31.

European Commission (2015). Eurostat Demography Report. Luxembourg: Publication Office of the European Union.

Farmer, E. And Lutman, E. (2010) Case management and outcomes for neglected children returned to their parents. A five year follow- up study. DCSF- RB214.

Felitti, V. J., Anda, R. F., Nordenberg, D., Williamson, D. F., Spitz, A. M., Edwards, V., ... \& Marks, J. S. (1998). Relationship of childhood abuse and household dysfunction to many of the leading causes of death in adults: The Adverse Childhood Experiences (ACE) Study. American journal of preventive medicine, 14(4), 245-258. 
Gilbert, R., Widom, C. S., Browne, K., Fergusson, D., Webb, E., \& Janson, S. (2009). Burden and consequences of child maltreatment in high-income countries. The lancet, 373(9657), 68-81.

Hamilton-Giachritsis, C. and Browne, K. (2005). A Retrospective Study of Risk to Siblings in Abusing Families. Journal of Family Psychiatry 19, 619-624.

Hegar, R. (2005). Sibling placement in foster care and adoption: An overview of international research. Children and Youth Services Review, 27, 717-739.

Henderson, G., Black, M. \& Lamb, D. (2014). Children whose first supervision requirements or Orders are at home with their parent(s): Analysis of data held by the Scottish Children's Reporter Administration. Stirling: Scottish Children's Reporter Administration. Available at: $\quad$ http://www.scra.gov.uk/wpcontent/uploads/2016/03/Children-on-SR-at-home-June-2014.pdf

Henderson, G. \& Hanson, L. (2015). Child Protection Orders. Stirling: Scottish Children's Reporter Administration. Available at: http://www.scra.gov.uk/wpcontent/uploads/2016/03/Child-Protection-Orders-Research-Report-2015.pdf

Henderson, G., Hanson, L., Kurlus, I., Hunt, M. \& Laing, A. (2015). Permanence Planning and Decision Making for Looked After Children in Scotland: Adoption and Children (Scotland) Act 2007. Scottish Children's Reporter Administration and the Scottish Government. Available at: http://www.gov.scot/Resource/0049/00490291.pdf

Hill, M., Welch, V., \& Gadda, A. (2017). Contested views of expertise in children's care and permanence proceedings. Journal of Social Welfare and Family Law, 39(1), 42-66.

Isumi, A., \& Fujiwara, T. (2016). Association of adverse childhood experiences with shaking and smothering behaviors among Japanese caregivers. Child abuse \& neglect, 57, 12-20. 
Jones, C. (2016). Sibling relationships of children in foster care and adoption: A review of international research. Children \& Society, 30(4), 324-334.

Lery B, Shaw TV, Magruder J. 2005. Using administrative child welfare data to identify sibling groups. Children and Youth Services Review 27: 783-791.

McCormick, A. (2010). Siblings in foster care: An overview of research, policy and practice. Journal of Public Child Welfare, 4, 198-218.

McSherry, D. Weatherall, K., Larkin, E., Fargas Malet, M., \& Kelly, G. (2010). Who goes where? Young children's pathways through care in Northern Ireland. Adoption and Fostering, 34(2), 23-37.

Meakings, S., Sebba, J. \& Luke, N. (2017) What is known about the placement and outcomes of siblings in foster care? An international literature review. Oxford: The Rees Centre

National Records for Scotland (2016). Vital Events Reference Tables 2015, Section 2: Adoptions and re-registrations. Retrieved on 19/4/2017 from https:/www.nrscotland.gov.uk/statistics-and-data/statistics/statistics-by-theme/vitalevents/general-publications/vital-events-reference-tables/2015/section-2-adoptions-and$\underline{\text { re-registrations }}$

Norman, R.E., Byambaa, M., De. R., Butchart. A., Scott. J. \& Vos, T. (2012). The longterm health consequences of child physical abuse, emotional abuse, and neglect: A systematic review and metaanalysis. PLOS Medicine, 9, 1-31. DOI: 10.1371/journal.pmed.1001349.

Norrie, K. (2013). Children's Hearings in Scotland. $3^{\text {rd }}$ Edition. Edinburgh: W. Green. 
Putnam- Hornstein, E., Webster, D., Needell, B., \& Magruder, J. (2011). A public health approach to child maltreatment surveillance: Evidence from a data linkage project in the United States. Child Abuse Review, 20(4), 256-273.

Putnam-Hornstein, E., Cleves, M. A., Licht, R., \& Needell, B. (2013). Risk of fatal injury in young children following abuse allegations: Evidence from a prospective, populationbased study. American journal of public health, 103(10), e39-e44.

Scottish Children's Reporter Administration (2013). Practice Direction 19. Orders, Warrant, Measures. Stirling: SCRA. Available at: http://www.scra.gov.uk/wpcontent/uploads/2016/03/Practice-Direction-19-Orders-Warrants-and-Measures.pdf

Scottish Children's Reporter Administration (2016). Statistical Analysis 2015/16. Stirling: SCRA. Available at: http://www.scra.gov.uk/wp-content/uploads/2016/10/Fullstatistical-analysis-2015-16.pdf

Scottish Government (2010). Getting It Right For Every Child. Practice Briefing 5. Analysing information using the resilience matrix. Edinburgh: Scottish Government.

Scottish Government (2011). Guidance on the Looked After Children (Scotland) Regulations 2009 and the Adoption and Children (Scotland) Act 2007. Edinburgh: Scottish Government.

Selwyn, J., Sturgess, W., Quinton, D. \& Baxter, C. (2006). Cost and outcomes of noninfant adoptions. London: British Association for Adoption and Fostering.

Selwyn, J., Wijedasa, D. \& Meakings, S. (2014). Beyond the Adoption Order: challenges, interventions and adoption disruption. London: Department for Education.

Shen, A. C. T., Feng, J. Y., Feng, J. Y., Wei, H. S., Hsieh, Y. P., Huang, S. C. Y., \& Hwa, H. L. (2016). Who gets protection? A national study of multiple victimization and child protection among Taiwanese children.Journal of interpersonal violence, 0886260516670885 . 
Shlonsky, A., Webster, D. \& Needell, B. (2003). The ties that bind: A cross-sectional analysis of siblings in foster care. Journal of Social Service Research, 29(3), 27-52.

Shulman, B. H., \& Mosak, H. H. (1977). Birth order and ordinal position: Two Adlerian views. Journal of Individual Psychology, 33(1), 114.

Sidebotham, P., Heron, J., \& ALSPAC Study Team. (2006). Child maltreatment in the "children of the nineties": A cohort study of risk factors. Child abuse \& neglect, 30(5), 497-522.

Stoltenborgh, M., van IJzendoorn, M. H., Euser, E. M., \& Bakermans-Kranenburg, M. J. (2011). A global perspective on child sexual abuse: meta-analysis of prevalence around the world. Child maltreatment, 16(2), 79-101.

Stoltenborgh, M., Bakermans-Kranenburg, M. J., \& van IJzendoorn, M. H. (2013). The neglect of child neglect: a meta-analytic review of the prevalence of neglect. Social psychiatry and psychiatric epidemiology, 48(3), 345-355.

Stoltenborgh, M., Bakermans- Kranenburg, M. J., IJzendoorn, M. H., \& Alink, L. R. (2013). Cultural-geographical differences in the occurrence of child physical abuse? A meta- analysis of global prevalence. International Journal of Psychology, 48(2), 81-94.

Tarren-Sweeney, M. and Hazell, P. (2005). The mental health and socialization of siblings in care. Children and Youth Services Review, 27, 821-843.

The Care Inquiry (2013). Making not breaking: Building relationships for our most vulnerable children. London: House of Commons.

The Children Act, 1989, ch. 41.

The Children (Scotland) Act 1995, ch. 36. 
Thomas, C. (2013). Adoption of Looked After Children: Messages from Research. An overview of the Adoption Research Initiative. London: British Association for Adoption and Fostering.

Vincent, S. \& Petch, A. (2012). Audit and Analysis of Significant Case Reviews. Edinburgh: Scottish Government.

Ward, H.; Brown, R. and Westlake, D. (2012) Safeguarding Babies and Very Young Children from Abuse and Neglect. Jessica Kingsley Publishers.

Wulczyn, F. \& Zimmerman, E. (2005). Sibling placements in longitudinal perspective. Children and Youth Services Review, 27, 741-763. 


\section{Table 1}

Birth order and decisions on compulsory measures to protect the child at the point of first referral to the Children's Reporter.

\begin{tabular}{lcccc}
\hline Decision made & $\begin{array}{c}\text { First-born } \\
\text { siblings }\end{array}$ & $\begin{array}{c}\text { Middle } \\
\text { siblings }\end{array}$ & $\begin{array}{c}\text { Last-born } \\
\text { siblings }\end{array}$ & Total \\
\hline Child Protection Order in place & $6(20 \%)$ & $9(21 \%)$ & $13(33 \%)$ & $28(25 \%)$ \\
\hline $\begin{array}{l}\text { Compulsory measures of } \\
\text { supervision are necessary - Arrange } \\
\text { Hearing }\end{array}$ & $11(37 \%)$ & $14(33 \%)$ & $18(46 \%)$ & $43(39 \%)$ \\
\hline $\begin{array}{l}\text { Compulsory measures of } \\
\text { supervision are not necessary }\end{array}$ & $13(43 \%)$ & $19(45 \%)$ & $8(20 \%)$ & $40(36 \%)$ \\
\hline Total & $30(100 \%)$ & $42(100 \%)$ & $39(100 \%)$ & $111(100 \%)$ \\
\hline
\end{tabular}

Table 2

Characteristics of sample used to test each hypothesis

$\begin{array}{ccccc} & \text { No. of } & \text { Birth order of } & \text { Mean total } & \text { Mean age } \\ \text { difference } & \text { last-born } \\ \text { Hypotheses } & \text { sibling } & \text { sibling with } & \text { maternal } & \text { between first } \\ \text { pairs } & \text { data } & \text { siblings in } & \text { and last born } \\ & \text { family } & \text { siblings with } \\ \text { data / months }\end{array}$

1. First-born children are older than last-born

children at first referral

2. Length of time from first referral to first compulsory measure is greater for first-born than for last-born children

3. First-born children are older than last-born children when they are first placed on compulsory measures

4. First-born children are older than last-born children when they are first accommodated

5. Of those children who are placed permanently away from home with strangers, more last-born than first-born children will be adopted
23

21 last-born, 2

3.1

58.2

latest-born

23

21 last-born, 2

3.1

58.2

latest-born

24

22 last-born, 2

3.2

64.0

latest-born

23
23 last-born, 1
latest-born

3.0

60.3

19

19 last-born

2.8

45.9 
Table 3

Means, standard deviations and statistical analyses for age at referral, first compulsory measures and first accommodation, and duration from first referral to first compulsory measures, for first and last-born siblings

\begin{tabular}{|c|c|c|c|c|c|c|c|c|c|}
\hline \multirow{2}{*}{$\begin{array}{l}\text { Whether } \\
\text { adjusted } \\
\text { for } \\
\text { national } \\
\text { trends }\end{array}$} & \multirow{2}{*}{ Sample } & \multirow{2}{*}{$\begin{array}{l}\text { No. } \\
\text { pairs }\end{array}$} & \multirow{2}{*}{ of } & \multicolumn{2}{|c|}{$\begin{array}{l}\text { Means \& (SDs) } \\
\text { /months }\end{array}$} & \multirow{2}{*}{$\begin{array}{l}\text { Mean difference } \\
\text { in sample \& } \\
(95 \% \text { CI for } \\
\text { population) } \\
\text { months }\end{array}$} & \multirow{2}{*}{$\begin{array}{l}\text { Violations of parametric test } \\
\text { assumptions }\end{array}$} & \multirow{2}{*}{ Statistical test results } & \multirow{2}{*}{$\begin{array}{l}\text { Cohen's } \\
d \quad \text { effect } \\
\text { size }\end{array}$} \\
\hline & & & & $\begin{array}{l}\text { First- } \\
\text { born }\end{array}$ & $\begin{array}{l}\text { Last- } \\
\text { born }\end{array}$ & & & & \\
\hline
\end{tabular}

H1. Age at first referral / CPO

\begin{tabular}{|c|c|c|c|c|c|c|c|c|c|}
\hline \multirow[t]{2}{*}{$\begin{array}{l}\text { Un- } \\
\text { adjusted }\end{array}$} & All cases & & 23 & $\begin{array}{l}28.8 \\
(28.4)\end{array}$ & $\begin{array}{l}3.8 \\
(8.5)\end{array}$ & $\begin{array}{l}25.0 \\
(12.0-38.0)\end{array}$ & None & $t(22)=3.985, p=.001$ & 0.83 \\
\hline & $\begin{array}{l}\text { Ex. } \\
\text { referrals }\end{array}$ & simultaneous & 21 & $\begin{array}{l}24.5 \\
(25.6)\end{array}$ & $\begin{array}{l}3.8 \\
(8.8)\end{array}$ & $\begin{array}{l}20.7 \\
(8.1-33.3)\end{array}$ & $\begin{array}{l}\text { Slight positive skew (Shapiro } \\
\text { Wilk, } p=.017 \text { ); } 1 \text { outlier }\end{array}$ & $\begin{array}{l}t(20)=3.423, p=.002 \\
Z=3.285, p=.001\end{array}$ & 0.75 \\
\hline \multirow[t]{2}{*}{ Adjusted } & All cases & & 19 & $\begin{array}{l}-39.0 \\
(28.7)\end{array}$ & $\begin{array}{l}-51.4 \\
(12.3)\end{array}$ & $\begin{array}{l}12.4 \\
(-3.1-27.9)\end{array}$ & None & $t(18)=1.684, p=.055$ & \\
\hline & $\begin{array}{l}\text { Ex. } \\
\text { referrals }\end{array}$ & simultaneous & 17 & $\begin{array}{l}-41.9 \\
(26.4)\end{array}$ & $\begin{array}{l}-50.8 \\
(12.4)\end{array}$ & $\begin{array}{l}8.8 \\
(-5.5-23.2)\end{array}$ & None & $t(16)=1.297, p=.106$ & \\
\hline
\end{tabular}

H2. Duration from first referral / CPO to first compulsory measures

\begin{tabular}{|c|c|c|c|c|c|c|c|c|c|c|}
\hline $\begin{array}{l}\text { Un- } \\
\text { adjusted }\end{array}$ & All cases & 23 & $\begin{array}{l}23.0 \\
(25.4)\end{array}$ & $\begin{array}{l}8.3 \\
(7.2)\end{array}$ & $\begin{array}{l}14.7 \\
(3.7-25.8)\end{array}$ & $\begin{array}{l}\text { Positively skewed } \\
\text { Wilk, } p=.001)\end{array}$ & (Shapiro & \multicolumn{2}{|c|}{$\begin{array}{l}t(22)=2.758, p=.006 \\
Z=1.734, p=.042\end{array}$} & 0.58 \\
\hline \multicolumn{11}{|l|}{ Adjusted } \\
\hline & All cases & 17 & $\begin{array}{l}-2.1 \\
(51.3)\end{array}$ & $\begin{array}{l}-32.4 \\
(20.3)\end{array}$ & $\begin{array}{l}30.4 \\
(4.2-56.5)\end{array}$ & None & & $\begin{array}{l}t(16)=2.465 \\
p=.013\end{array}$ & 1-tailed & 0.60 \\
\hline
\end{tabular}


H3. Age at first compulsory measures

\begin{tabular}{|c|c|c|c|c|c|c|c|c|}
\hline \multirow[t]{2}{*}{$\begin{array}{l}\text { Un- } \\
\text { adjusted }\end{array}$} & All cases & 24 & $\begin{array}{l}55.5 \\
(39.5)\end{array}$ & $\begin{array}{l}12.3 \\
(12.0)\end{array}$ & $\begin{array}{l}43.2 \\
(26.3-60.0)\end{array}$ & $\begin{array}{l}\text { Slight positive skew (Shapiro- } \\
\text { Wilk, } p=.017 \text { ) }\end{array}$ & $\begin{array}{l}t(23)=5.294, p<.001 \\
Z=4.186, p<.001\end{array}$ & 1.08 \\
\hline & Ex. simultaneous SRs & 15 & $\begin{array}{l}53.5 \\
(43.0)\end{array}$ & $\begin{array}{l}9.1 \\
(7.9)\end{array}$ & $\begin{array}{l}44.4 \\
(20.0-68.8)\end{array}$ & None & $t(14)=3.904, p=.001$ & 1.01 \\
\hline \multirow[t]{2}{*}{ Adjusted } & All cases & 22 & $\begin{array}{l}-45.6 \\
(39.2)\end{array}$ & $\begin{array}{l}-81.9 \\
(13.8)\end{array}$ & $\begin{array}{l}36.3 \\
(18.9-53.6)\end{array}$ & $\begin{array}{l}\text { Slight positive skew (Shapiro- } \\
\text { Wilk, } p=.025 \text { ) }\end{array}$ & $\begin{array}{l}t(21)=4.346, p<.001 \\
Z=3.750, p<.001\end{array}$ & 0.93 \\
\hline & Ex. simultaneous SRs & 13 & $\begin{array}{l}-51.82 \\
(41.91)\end{array}$ & $\begin{array}{l}-84.74 \\
(7.95)\end{array}$ & $32.9(6.9-59.0)$ & None & $t(12)=2.751, p=.009$ & 0.76 \\
\hline \multicolumn{9}{|c|}{ H4. Age at first accommodation } \\
\hline $\begin{array}{l}\text { Un- } \\
\text { adjusted }\end{array}$ & All cases & 23 & $\begin{array}{l}58.35 \\
(46.46)\end{array}$ & $\begin{array}{l}12.00 \\
(23.79)\end{array}$ & $46.3(30.2-62.5)$ & $\begin{array}{l}\text { Positive skew (Shapiro-Wilk, } p \\
=.010 \text { ) }\end{array}$ & $\begin{array}{l}t(22)=5.944, p<.001 \\
Z=4.198, p<.001\end{array}$ & 1.24 \\
\hline
\end{tabular}

Note. All $p$ values are 1-tailed. CI is confidence intervals. CPO is child protection order. SR is supervision requirement. Cohen's $d$ calculated for significant results only. 